\title{
Towards a Personalised, Learning Style Based Collaborative Blended Learning Model with Individual Assessment
}

\author{
Ilona BÉRES ${ }^{1}$, Tímea MAGYAR ${ }^{1}$, Márta TURCSÁNYI-SZABÓ2 \\ ${ }^{1}$ Budapest College of Communication and Business, Dept. Methodology \\ Nagy Lajos király útja 1-9, 1148 Budapest, Hungary \\ ${ }^{2}$ Eotvos Lorand University, Faculty of Informatics, Dept. Media \& Educational Informatics \\ Pázmány Péter sétány 1/c., 1117 Budapest, Hungary \\ e-mail: iberes@bkf.hu,tmagyar@bkf.hu,tszmarta@inf.elte.hu
}

Received: September 2011

\begin{abstract}
In this paper we aim to describe the process by which our personalised web-based collaborative teaching/learning methodology (CECIP - Collaboration - Evaluation - Critical thinking Individual assessment - learner Profile) evolved originating from Vygotsky's theory and based on the (C) collaborative construction of student's knowledge, (E) developing evaluation and assessment skills, (C) developing critical thinking skills, (I) integrating individual evaluation and (P) generating learner profile. Our CECIP methodology integrates individual learning style dimensions and their preferences into e-learning environment by filling out MBTI, Gardner, GEFT and FelderSilverman questionnaires during our four-semester-research. The paper covers the theoretical foundations of Learning Styles giving analogies to preferred learning strategies. A three-part-research process is described through which the described CECIP model emerged: (1) analysing Learning Styles and Learning Management Systems that claim to support their work; (2) raising the background knowledge of students in cognitive psychology in order to improve design and evaluation methodologies of multimedia learning materials; (3) personalising tasks and assessment based on Bloom's Taxonomy.
\end{abstract}

Keywords: blended learning, learning style, online collaboration, statistical approach.

\section{Introduction}

The Internet and the increased role of web 2.0 technologies, the spreading of the usage of wikis, blogs and forums have been changing the nature of learning. The development of complex problem solving skills, preparation of non-routine tasks, finding and using permanently broadening information sources, working in projects, keeping up with permanently changing needs, are requirements that students in higher education can fulfil if they are aware of their own learning strengths and weaknesses and with the most efficient learning strategies in their own learning process and particular learning situation. The integration of technology into the learning process means that students have to be more autonomous learners; hence the understanding of their own learning is essential. 
The growth in demand for electronic courseware results in the increase of importance for defining more suitable qualitative criteria for e-learning products both for business and education. The development of effective and quality online curriculum is crucial to the identification of the necessary skills and abilities for the present age. Today's aims, in line with the European Union recommendation for 'life long learning', are the following (LLL Programme of the EU):

- critical thinking and problem-solving skills;

- communicative skills;

- creativity and innovation skills;

- collaboration skills;

- contextual learning skills;

- information and media literacy skills.

These are the cognitive skills which are absolute necessities in our present age. They are important competencies, skills, which need innovative learning/teaching methods for their integration. The online learning and knowledge-building model must be flexible, adaptable, built on features of connectivism (Siemens and Tittenberg, 2009) to satisfy the continually changing environment. E-education in most cases is not pedagogy - but technology driven which, in many cases, actually worsens the effectiveness and efficiency of learning. Most of the problems appearing during the practice of e-learning and blendedlearning could be abolished upon careful analysis and the right use of learning theories.

Deterministic factors of electronic educational contents are the assurance of the effective learning process, efficient educational contents and educational environment. Apart from these, the learners' opinions and needs are important factors, too, which need to be considered when designing e-learning materials. A successful learning process demands that teaching methods respect learning differences. Cognitive styles are one of several important factors to be considered by designers of e-learning courseware (Béres et al., 2008a; Coffield et al., 2004).

At the beginning of the 20th century Vygotsky created a theory which was based on obvious practical experience. According to Vygotsky, real education is not acquiring specific knowledge and skills, but acquiring the ability to learn: clear, creative thinking, designing, implementing, and communicating the meaning in different aspects. Therefore, he considered as most important the development of those cultural instruments which can help in thinking and creating. Such instruments are languages and other symbol systems (including the basic symbol system of multimedia). Vygotsky explained the impact of thought and language on each other in his most important works and introduced the definition of the "zone of the proximal development" (Vygotsky, 1978, 1986). Based on this, we can say that the different emerging grouped learning methods originate from this theory because the root of team work is within appropriate communication and the diversity of co-workers giving a chance to extend each others' knowledge potential.

To reach the efficiency of e-learning it is an acknowledged fact that it is not enough only to implement the "e-", it is important to have personal, teacher led educational orientation which helps the process of "learning", which is often mentioned as a composite educational environment: "blended-learning". Latest researches indicate that learning 
should be interpreted as a social process, where all of the individual participants (learners/students) are responsible for their own knowledge-building. Today the aim of learning is not to learn facts, but to generate a flexible and creative knowledge-base which can be applied in different situations (Carliner and Shank, 2008; Miyake 2007). To achieve this aim, apart from including teachers' interactive orientation scheme, we have to be able to address students' differences, integrate student centred activities, problem-based approach, high interaction rates built on features of connectivism, reflection and evaluation, as well as collaborative knowledge-building.

Thus, we started our own research by analysing theories of cognitive differences in the different forms of learning styles (their characteristics, measuring methods and relevancies), analysing student differences (identifying the main instruments that characterise well established differences, if they do exist), analysing different environments and the use of methodologies (gaining feedback from students' preferences, attitudes and attained results) in order to come up with a usable practical learning model that is based on theory, yet can be effectively implemented in practice.

\section{Theoretical Background}

Cognitive style is usually described as a personality dimension that influences attitudes, values and social interactions. Learning style is a complexity of cognitive parameters which is relevant for the learning process (Triantafillou et al., 2004). Therefore learning style is a subset of cognitive style. The field of learning styles is not unified, and is divided into three linked areas of activity: theoretical, pedagogical and commercial (Coffield et al., 2004).

The Learning \& Skills Research Centre identified 71 models of learning styles and categorised 13 of these as major models, emphasizing some models because of their popularity. In the United States for example the Dunn \& Dunn learning style model is used in many primary schools; while in the UK, both Kolb's Learning Style Inventory (LSI) and Honey \& Mumford's Learning Style Questionnaire (LSQ) are widely used. It is necessary to analyse the assessment of different learning style models and their pedagogic consequences more deeply because of their complexity and debated nature.

International research is divided upon the crucial distinctiveness of personality depending on learning styles, some strongly accept it (Coffield et al., 2004; Felder and Silverman, 1988; Triantafillou et al., 2004), and some strongly object (Coffield et al., 2004), yet a thorough analysis and its careful implementation can be a helpful indicator for both teacher and learner, which has been the main guiding principle during our own research work.

Five families of learning style models can be distinguished according to scientific literature (Coffield et al., 2004): constitutionally based learning styles and preferences, cognitive structure, stable personality type, "flexibly stable" learning preferences, learning approaches and strategies. A lot of models exist for learning styles, many of which employ the quadrant approach to the style definition. 


\subsection{Theoretical Foundations of Learning Styles}

\subsubsection{Honey \& Mumford}

The model classifies learners into four distinct learning styles. The activists prefer interactive activities. The pragmatists need to be able to link the activities directly to their own work and require relevance. The theorists need conceptual framework as maps, providing direct links to concepts and workflow diagrams. The reflectors like to engage in deep thinking and prefer to be able to print the courseware documentation to read and digest at their leisure prior to attempting activities (Cook, NA). When presented with online content, each learning style displays a preference (Henke, 2001): reflectors prefer self-assessment exercises, activists prefer role-playing and scenarios, theorists prefer discussion groups, pragmatists like problem solving.

Figure 1 demonstrates a learning style with a strong activist preference, moderate theorist and pragmatist preferences and a low reflector preference.

\subsubsection{Kolb}

Kolb's division of learning styles (Cook, NA) shows the following preferences (Henke, 2001): Convergers want to solve problems and rely upon deductive reasoning. Divergers view situations from many perspectives relying on brainstorming and idea generation. Assimilators use inductive reasoning and theoretical models. Accommodators carry out plans and experiments. Pimentel (1999) noted how even within academic fields that learning environments for these fields vary considerably (Fig. 2).

\subsubsection{Myers-Briggs Type Indicator (MBTI)}

MBTI typology has four main dimensions (Coffield et al., 2004): (1) Preference to focus attention - either in the outside world (extraversion) or in our heads (introversion). (2) Preference to absorb and process information - both literally and stepwise (sensing) or generally and in patterns (intuition). (3) Preference to prioritise in decision making - either logical and objective (thinking) or value based and people oriented (feeling). (4) Preference in style of living and working - either scheduled and organised (judging) or spontaneous and flexible (perceiving).

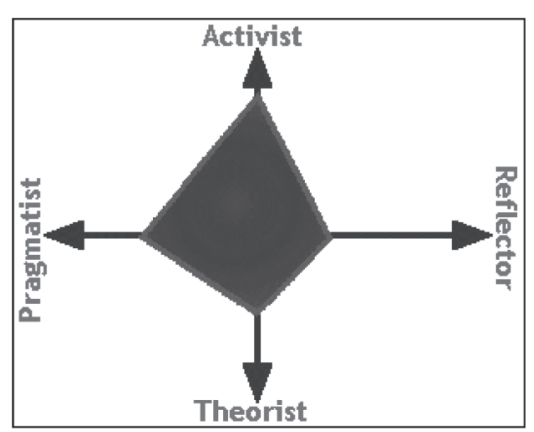

Fig. 1. Honey \& Mumford learning style quadrants.

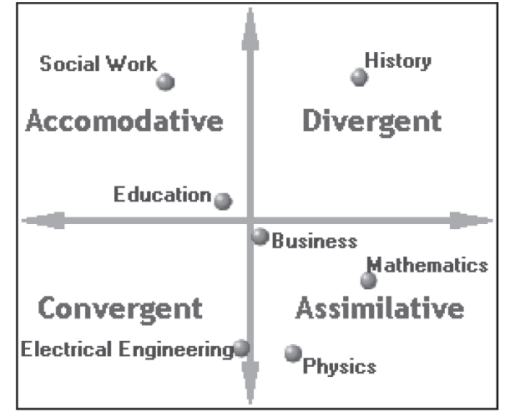

Fig. 2. Kolb learning style quadrants. 


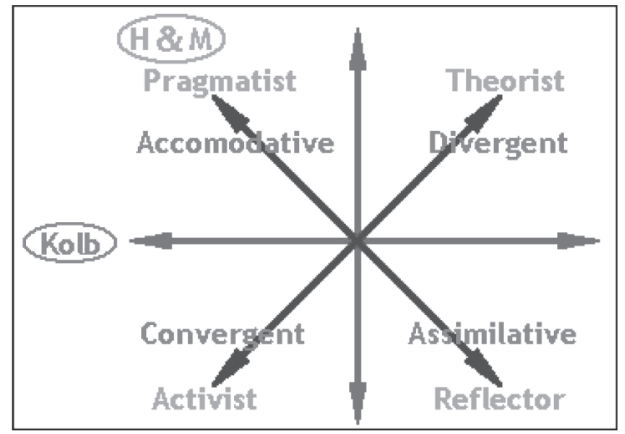

Fig. 3. Convergence of Kolb and Honey \& Mumford models (Coffield et al., 2004; Cook, NA).

According to the attained results alongside the above dimensions, 16 styles can be distinguished.

We also used Keirsey's four temperaments theory for learning styles and online attitude analysis. Keirsey put the 16 MBTI groups into 4 categories: rational type (NT intuitive thinking, strategic intellect), idealist type (NF -intuitive feeling, diplomatic intellect), artisan type (SP - sensory perception, tactical intellect), and guardian type (SJ sensory judgement, logistical intellect; Keirsey, 1998).

\subsubsection{Felder-Silverman Learning Style Model}

In Felder-Silverman (1988) learning style model (FSLSM) learners are described on four dimensions. These dimensions are how learners prefer to process (active/reflective), perceive (sensing/intuitive), receive (visual/verbal), and understand (sequential/global) information.

The active/reflective dimension is analogous to the respective dimensions in Kolb's model. Active learners learn best by working actively, by applying the material, and by trial-error. They prefer to learn by working in groups. Reflective learners prefer to think about and reflect on the material. They prefer to work alone or in small groups.

The sensing/intuitive dimension is taken from the Myers-Briggs Type Indicator and has also similarities to the sensing/intuitive dimension. Sensing learners like to learn facts and concrete learning material. They like to solve problems with standard approaches and also tend to be more patient with details. Sensing learners are considered as more realistic and more practical than intuitive learners. Intuitive learners prefer to learn theories and their underlying meanings, with general principles rather than concrete instances as a preferred source of information.

The visual/verbal dimension: Visual learners learn better what they see (diagrams, demonstrations, flow charts, mindmaps). Verbal learners like written and spoken explanations (discussions, written texts, narrations).

The sequential/global dimension: Sequential learners learn in small linear steps. They follow logical steps in finding solutions. Global learners tend to absorb learning material as a whole picture. They are more interested in overviews. (Felder and Silverman, 1988; Felder, 1993). 


\subsubsection{Gardner's Multiple Intelligences}

According to Gardner's multiple intelligences theory, learners have nine different kinds of intelligences which represent differences of individuals and reflect different ways of interaction. Intelligences proposed by Gardner are: spatial, linguistic, musical and logicalmathematical, and more novel intelligences such as bodily kinaesthetic, naturalist, interpersonal, intrapersonal and existential. According to Gardner, every single person is a single combination of these. This theory suggests that designing any learning material should be as flexible as possible to meet the diverse needs of all learners (Holmes and Gardner, 2006).

\subsubsection{Field-Dependence and Field-Independence}

The dimension of field-dependence/independence expresses the preference of the individual towards the environment, which could be global (field-dependent) or analytical (fieldindependent). A field-dependent person prefers global concepts and categories, while a field-independent one can better discriminate details, prefers information of more specific concepts and categories. Field-dependence/independence can be measured with the GEFT (Group Embedded Figures Test) or the HFT (Hidden Figures Test). These tests measure a type of cognitive perceptual ability rather than a cognitive style (Rittschof, 2008). This has huge importance, since learning styles are properties of individuals which can not change in a life-span, while abilities can be developed.

\subsubsection{Relationship Between Learning Types and E-Learning}

Research indicates that students with different cognitive styles choose different learning strategies for learning (Triantafillou et al., 2004). In an ideal educational environment the learner can change learning strategy according to their own needs. Research proves that autonomous interactive instructional features could benefit field-independent learners, but may be difficult for field-dependent learners who need increased structure and guidance (Béres et al., 2008b; Béres, 2009; Rittschof, 2008).

Thus, our analysis of theoretical studies helped us identifying the main indicators of learning styles and made us produce test instruments (mainly electronic, except for the GEFT test which is a paper-pencil test) in order to test all our students, while immersing

Table 1

Strategies supporting different learning types (Triantafillou et al., 2004)

\begin{tabular}{|c|c|c|}
\hline & Field-dependent learner & Field-independent learner \\
\hline Material set-up & $\begin{array}{l}\text { Global approach from général to } \\
\text { spécifie }\end{array}$ & $\begin{array}{l}\text { Analytical approach, from spécifie } \\
\text { to général }\end{array}$ \\
\hline Control & (Built-in) program-control & Learner control with menu \\
\hline Guidance & $\begin{array}{l}\text { Explicit May of access, maximal } \\
\text { guidance }\end{array}$ & $\begin{array}{l}\text { Individual way of access, minimal } \\
\text { guidance }\end{array}$ \\
\hline Feedback & Maximal & Minimal \\
\hline Contents organization & Advance organiser & Post organiser \\
\hline Structure & Structured lessons & Allow to develop own structure \\
\hline
\end{tabular}


them in different learning environments and situations, to gain knowledge about evolving characteristics (if such can be identified) and the effectiveness of embedding such characteristics into the options of knowledge-building methodology.

Based on the literature we can summarise that the learning styles of individuals play an important role in digital teaching/learning environments. The field of learning style is detailed but there are some controversial issues in the literature. An important controversial issue deal with learners' achievement. There is no incontrovertible empirical proof that the teaching approach which supports individuals learning styles has significantly positive effect on students' efficiency (Coffield et al., 2004). On the other hand many researchers consider learning styles being an important factor in education. They state that learners with strong learning style preferences may have difficulties when teaching styles do not support their learning styles (Felder and Silverman, 1988). Others recommended that learners should also strengthen their weaknesses by using unfitting teaching methods (Kolb, 1984). Based on Brogan's theory, individual learners' needs play central role in technology enhanced learning. Each learner has individual traits: cognitive trait, learning styles, prior knowledge, attitude and social features (Brogan, 2008). So we think that different learning styles, individuals' attitudes and preferences are important but not unique factors during the learning process. We think that it is important to take into account these features when designing an online learning/teaching model. When teachers are acquainted with students learning styles, they can use consciously matching or mismatching teaching approaches. In our particular model for our multimedia content developer students it is essential for them to understand the significance of this in e-learning.

\subsection{Review of Existing E-Learning Models}

Before building our learning model we made a review of existing e-learning models. The field of online learning is growing continuously. There are different approaches for effective online teaching and learning. Anderson (2008) argues that effective learning is community-centred, knowledge-centred, learner-centred, and assessment-centred. In the learner centred approach activities are used for exposing student's prerequisite knowledge. Knowledge centred contextual thinking skills and techniques are the most important features of effective learning. Assessment centred models consider formative and summative assessment as the necessity for effective learning environments. Community centred approach considers how students can work collaboratively within an online learning environment in order to create new knowledge.

\subsubsection{Anderson's Online Learning Model}

Anderson combines collaborative, community of inquiry and community of learning into one model. The model illustrates the students and teachers, and their interactions with each other and with the content. Learners can interact directly with any content. Community models generally cannot serve larger numbers of students (Anderson, 2008).

\subsubsection{Collis \& Moonen's Flexible Learning Approach}

Collis \& Moonen in their work identify 19 dimensions of flexibility and then discussed ways in which institutions can introduce technology to provide increased flexibility along 
a fixed/less flexible/more flexible continuum model. The model relates all aspects of flexibility to two simple pedagogical dimensions: acquisition and contribution. A flexibility activity framework is then described on types of technology, both core and complementary, current and future. The main flexibility dimensions in the model are (Collis and Moonen, 2004):

- time;

- content of the course;

- entry requirements;

- instructional approaches and resources;

- delivery and logistics.

\subsubsection{Salmon's Five Stage Model}

This online learning approach builds upon each previous steps (Salmon, 2002):

- Stage 1 -Access \& Motivation: The main focus of this stage is on exploring the technology and access to it. Winning the learner's trust is the main goal. Time is also spent on motivating participants; e-tivities are organised around this.

- Stage 2 - Socialisation: Building on the first stage, this stage focuses on social processes and 'community building'.

- Stage 3 - Information Exchange: This stage revolves around exchanging information and performing tasks. Interaction takes place on two levels, namely within the course content and between other participants and the moderator.

- Stage 4 -Knowledge Construction: Knowledge development is central to this stage. Discussion activities and group dynamics play a major role, too.

- Stage 5 -Development: This stage is characterised by reflection and group learning.

\subsubsection{McLoughlin's Inclusive Pedagogical Model}

McLoughlin proposed a pedagogical framework that emphasizes the internationalization of learning resources based on a constructivist approach, to provide flexibility and plurality to the learning situation. This model integrates real world activities and active student participation. The acquisition of knowledge is a process that is both social and individual (McLoughlin, 2007).

In the literature of online learning research we can see an increasing focus on student centred methods and environments. Our work focuses on a real learner centred approach where each student is attended as an individual person Our model to integrate all the effective features summarised in the above literature review and attempts to give a practical model for achieving personalised collaborative learning within a blended learning frame.

\section{Aims of the Research Process}

Our aim was to develop a web-based environment to support effective collaboration with an output of a model that can be well adapted within higher education. This model integrates the following: 
(1) addressing individual needs, preferences and learning styles which help to generate effective project teams;

(2) developing critical thinking and problem solving skills;

(3) developing sensitive evaluation skills;

(4) supporting online collaboration among students resulting in knowledge-building;

(5) allowing the tracing of individual capacity and added values.

We developed our model with taking the above criteria into consideration in order to enhance effectiveness and efficiency.

The exploration focused on the students needs, attitudes and experiences, and was guided by the following research questions: Which learning style model is most relevant? Which are the different learning style dimensions, e-learning preferences and how can they be integrated within blended learning environment? What makes blended learning personalised and effective? What are the students' experiences with our blended learning models?

\section{Research Methods and Process}

The main objective of our paper is to analyse the students' attitudes and experiences in a collaborative context of our blended learning model. This work contains case studies of the course "Designing multimedia materials" at ELTE University. The duration of the course is one semester. The subjects of our four-semester-research were program designer and informatics teacher training students, in their fourth and fifth year of the university studies. In this chapter we shall describe our developing methodology, the process in which we refined our evolving environment, syllabus and course setup that attempts to integrate all requirements described in the above chapter. The process of research can be divided into three distinguished parts:

(1) identifying Learning Styles and assessing students with two different environments claiming to support different Learning Styles;

(2) raising the background knowledge of students in cognitive psychology in order to gain a better understanding of the design and evaluation principles of multimedia learning materials;

(3) personalizing individual work of team members and assessing their work in order to fine-tune the CECIP model.

\subsection{First Semester of Our Research}

The first step of our research was to define the cue of learning styles in e-learning, and the students' attitudes with different learning styles in electronic learning environment. The aim of our project was to compare and make the effectiveness and efficiency of learning measurable which were built into two different e-materials.

To realize our aim we made an experiment in which the same experimental learning material was adapted within two different frameworks. The function of these frames was 
to provide technical background for the experiment in relation to the course of designing multimedia materials. Besides, we analyzed how the frameworks supported different learning styles and tried to identify conditions which efficiently supported autonomous and active learning.

\subsubsection{The Frameworks}

One version of the experimental material was inserted into a self-expanding innovative frame based on Flash technology. Bigger units, chapters, and tasks were visualised by an overview mindmap combined with using a PHP framework programme which was made for this purpose. So we combined the webpages, materials in the same chapter, according to the inner logical connection to the build up of the curriculum. The portal contained the curriculum related tests. We had particular, traceable logfiles from all of the students' activities, since every click were stored in a database. We know (within the precision of a second) where students clicked in a page, and from the elapsed time between the data we can calculate how much time they spent learning that part of the material. These logfiles were saved including user names of students ${ }^{1}$.

The other version of the experimental learning material was placed in an SAP framework (http: //www. sap.com/index.epx, http://www.sap.com/hungary/ index.epx), that claimes to take learning strategies into consideration while building curriculum and learning structure. This approach is suitable for creating tailor-made learning paths fitting chosen strategies. The CooSpace e-learning system (with SAPbased database) used was SCORM-based so we needed to build the curriculum from logical self-supporting units considering reusing. Accordingly, first we had to decontextualise the material, after that from the primary pieces, build up the curriculum structure with necessary logical relations. We had to plan carefully the elements in order to build a course structure that mirrors a coincise concept of the given material. Thus the module contained orientation, explanation, examples and instructional elements from which the Content Management System built different trails for students with different Learning Styles. Containing: only orientation; orientation at the beginning; explanation centred; example centred; content centred elements.

\subsubsection{Experimental Learning Material}

The experimental material interpreted two topics: the topic of perception (Fig. 4) and hearing, which is indirectly relevant to the multimedia design course, but is not directly part of it, since it examined the process of cognition on a biological basis. In this manner we guaranteed equal opportunity of background knowledge between the students and at the same time the motivation for acquisition of the curriculum. Students could check their results within the self-assessment tests at the end of each chapter.

In the course of the experimental curriculum students could use different representations (texts and graphics; audio and animation) and they could choose different ap-

\footnotetext{
${ }^{1}$ The learning material and the utilised frameworks was originally developed by ourselves for the Kaleidoscope 507838 Network of Excellence [http: / /www. noe-kaleidoscope.org/pub/]: "Interaction between learner's internal and external representations in multimedia environment" research project, which we adapted here for this experiment.
} 


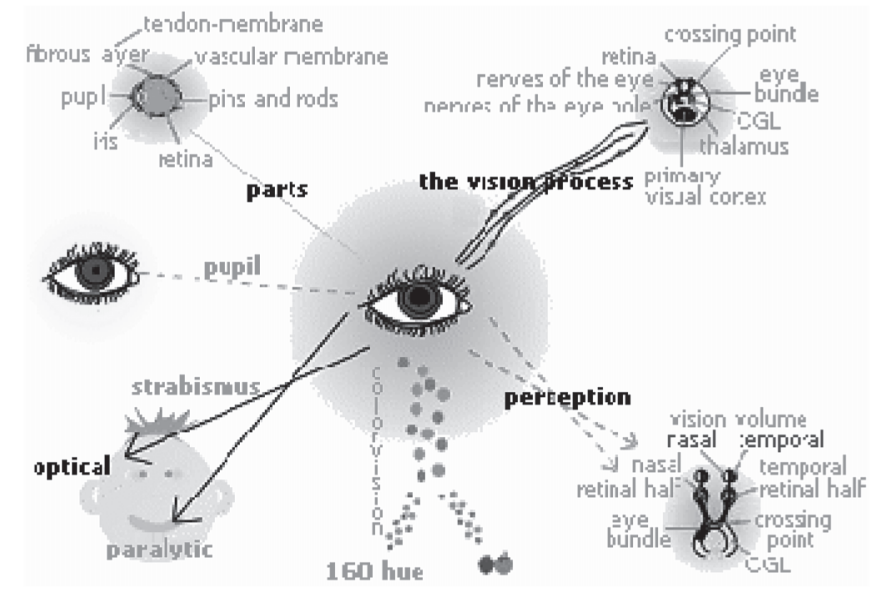

Fig. 4. Overview mindmap in PHP version.

proaches provided by the different systems (sequential in SAP and global approach in PHP versions). Figure 4 shows the integrated mindmap for the chapter on perception. We compared the students' attitudes, logged by the framework system with their identified learning styles.

\subsubsection{Results of the Experiment}

In this experiment (and the course of the semester) 101 students participated. Participants filled out a GEFT test on paper and an online MBTI test before learning from the experimental curriculum.

The MBTI tests were filled out by 86 students, the gender distribution was: $73 \%$ male and $27 \%$ female. Almost a quarter $(23 \%)$ of the students was ISTJ type (introverted, sensing, thinking, judging), a little bit less (13\%), but also ESTJ (extroverted, sensing, thinking, judging) was dominant. If we examine the effect of a single factor, then the sensing (77\%) and thinking (70\%) factors dominate, the combination of these two factors was present in more than half $(52 \%)$ of the students styles. The gender gap was significant; the difference between thinking (in favour of males) and feeling (in favour of females) types was almost $30 \%$.

The GEFT test was filled out by 99 students. We didn't find significant differences between male and female group in test results. The majority of the students (91\%) were found to be field independent.

\subsubsection{Final Test Results}

The final test was filled out by 93 students. They attained 57 points as an average from the maximum of 80 points, with the deviation of $13.57 .15 \%$ of the students attained below average, and the same percentage performed above the average. We didn't find significant differences between the students using different frameworks. Students with different majors showed significant differences: the programmers' average (73\%) was much better then that of the informatics teachers $(63 \%)$. 
By sorting the students' averages in different groups of learning styles, and analysing them, we could see that the $\mathrm{N}$ (intuition) type students had the smallest average, and the $\mathrm{S}$ (sensing) types the biggest. Table 2 shows differences between learning style and learning performance. The type identified as idealist type by Keirsey (NF) got the weakest result, but in our online course S (sensing) and SP (artisan) types performed better than the others.

We have detailed information about the learners' activities due to the logging technology integrated in the system. To analyse the learners' attitudes and the learners' activity in the online learning environment we could find differences between the attitudes of students with different learning styles using the online learning environment. The table below shows students preferences within the online course:

Table 2 summarizes the results of our analysis. It can be seen that sensing learners spent more time with the learning content than intuitive learners. Sensing students more often used mindmap navigation approaches than others. This behaviour indicates that sensing learners were interested in this learning approach and they made use of it throughout their learning. The intuitive students focus more on self-assessment tests and less time with acquisition of the learning content. The analysis on behaviour of students showed that our online course fits well with S and SP students, who are motivated in discovering learning content is their own way and we have to ingrate other activities to meet better the preferences of NF types.

In order to collect a wider range of information about the students' experiences and opinions we asked them to fill out an anonym questionnaire every semester. This ques-

Table 2

Performance and preferences of students with different learning styles in the on-line environment

\begin{tabular}{|c|c|c|c|c|c|c|}
\hline Task & $\begin{array}{l}\mathrm{S} \\
n=63\end{array}$ & $\begin{array}{l}\mathrm{N} \\
n=23\end{array}$ & $\begin{array}{l}\text { SJ } \\
n=41\end{array}$ & $\begin{array}{l}\text { SP } \\
n=19\end{array}$ & $\begin{array}{l}\mathrm{NF} \\
n=8\end{array}$ & $\begin{array}{l}\text { NT } \\
n=18\end{array}$ \\
\hline Average & 63.8 & 51.7 & 58.0 & 62.1 & 51.3 & 56.0 \\
\hline Performance & $80 \%$ & $65 \%$ & $74 \%$ & $78 \%$ & $64 \%$ & $70 \%$ \\
\hline Learning content visit & & $\checkmark$ & & $\checkmark$ & & $\checkmark$ \\
\hline $\begin{array}{l}\text { Time spent more } \\
\text { than average }\end{array}$ & $\checkmark$ & & $\checkmark$ & $\checkmark$ & & \\
\hline Mindmap use & $\checkmark$ & $\checkmark$ & $\checkmark$ & $\checkmark$ & & $\checkmark$ \\
\hline Mindmap navigation & $\checkmark$ & & $\checkmark$ & & & \\
\hline Sequential navigation & & $\checkmark$ & & $\checkmark$ & & $\checkmark$ \\
\hline Choose text & & & & $\checkmark$ & & \\
\hline Choose audio & & & & $\checkmark$ & & \\
\hline Choose graphics & $\checkmark$ & & & $\checkmark$ & $\checkmark$ & $\checkmark$ \\
\hline Choose animation & $\checkmark$ & & $\checkmark$ & $\checkmark$ & $\checkmark$ & \\
\hline Self assesment test & & $\checkmark$ & $\checkmark$ & & & $\checkmark$ \\
\hline Need help & $\checkmark$ & & $\checkmark$ & & & \\
\hline
\end{tabular}


tionnaire contained 23 five grade Likert scale questions. The feedback questionnaire was mandatory. Before filling out the questionnaire students were informed about its aims: hence their answers helped us in understanding their experiences during the learning process; and helped us in refining our blended learning model. Students could express their opinion about their own learning styles, could evaluate their own activities, products and the implementation of objectives in an online questionnaire.

According to the students' opinion in electronic learning environments, it is very important for the learner to be allowed to learn in their own style, this criterion may be the key to successful learning. More than half of the students think that the learning process is more efficient if a printed version of course is available. Some students did not understand the exact task. This indicates the importance of precise transmission of information. $77 \%$ of the students believe that the most effective learning method in higher education is through lectures with active student involvement (41\%), prefer materials to be also available through e-learning (36\%). The results of the questionnaire indicate that the respondent students consider that the blended learning method is the most efficient one, and there is also strong demand for tutorial support (Béres et al., 2008b).

\subsubsection{Conclusion of the First Semester of Our Research}

Based on our students' performance it can be seen that there was no significant difference between the results of students using different systems. We found differences in efficiency of students with different learning styles. These results can be explained by the effect that the applied approaches and learning activities didn't fit to all learning styles. Analysing $\log$ files we can notice the fact that the students with different styles choose different approaches.

\subsection{Fortification of Conscious Methodology Development}

In the next step of our research we wanted to strengthen the cognitive psychological background of students for designing and evaluating multimedia materials using conscious interpretation of learning styles and critical thinking.

From this point on a single framework BSCW was used by all the students that allowed the identification of added value of collaborative work by precise registration of the individual's activities. Students worked in groups of four, taking responsibility for developing different media elements (a. video and audio, b. text and mindmap, c. graphic and animation and d. interactive simulation). Each person in the group had to choose one of these tasks and work together to create a coherent result. Their project goal was development and integration of multimedia elements fitting to selected chapters of an electronic learning material.

According to our previous semester's results, we developed a methodology in which the identification of students' learning styles and preferences had an important role. The goal of the course was to make students become aware of the efficiency factors of elearning content and master authoring tools with which they can realise required features. The development of multimedia content demands various expertises. Our students got 
acquainted with the importance of visual, auditive elements and with the significance of cognitive style that can be effective in e-learning materials.

We developed our model so the students of any learning styles and types could find their appropriate learning methods, tasks and activities. At the same time we also concentrated on helping students in acquiring the assessment methodology of multimedia content. Parts of applied methodology:

- We outlined the theory of learning styles and we analysed their role within elearning during an interactive lecture.

- By using the most relevant learning style instruments we identified students' learning styles and discussed their preferences.

- We presented useful applications for developing e-learning contents that are fit for different learning styles and learning strategies.

- The model integrated both theoretical and practical training; learning in both real class and virtual environments; learning alone and in groups. The theoretical and practical learning contents were available online during the whole semester.

- Declaring golden rules students created an online knowledge-base. Thus each student contributed in a wiki area adding what they found most important after reading the chapters assigned to them and their working group. All students could access the full range of golden rules. The golden rules are important guidelines, principles for e-learning content development theory and practice.

- As part of knowledge building, students evaluated the project works of those submitted in the previous year which developed critical thinking. Students also had an opportunity to analyse the applicability of the auditive and visual elements in particular applications.

- At midterm, student teams presented their works and evaluated each other's together with the teacher. At the end of the semester the teams had the opportunity to improve their work and to present and evaluate the improved version again.

\subsubsection{Results of Our Applied Learning/Teaching Method}

We used this model which takes into account students' learning style and preferences for two semesters with a total 156 (I semester $n=67$; II semester $n=89$ ) students.

Students filled out a paper-based GEFT test and an online MBTI test in both semesters. To have more information about online learner preferences, learning styles, and effective strategies of the different styles, in the second semester students also filled out Gardner tests. We asked students' opinion with an online questionnaire, too.

The MBTI test was filled out by 125 students (I. $n=42$; II. $n=83$ ), the gender distribution was: $62 \%$ male and 38\% female. 18\% of the students was ISTJ (introverted, sensing, thinking, judging), and 15\% was ESTJ (extroverted, sensing, thinking, judging) type. If we examine the effect of a single factor, then the sensing (82\%), thinking (68\%) and judging $(66 \%)$ factors dominate. These results are similar to the previous semester.

The GEFT test was filled out by 131 students (I. $n=51$; II. $n=80$ ). We didn't find significant differences between male and female group in the test results. The majority of the students were field independent (91\%), which (based on our measurements) can be called typical for programming students. 
The Gardner test was filled out by 76 students. We found that $43 \%$ of our students were logical-mathematical and $25 \%$ are interpersonal. These two intelligences are dominant. Most of the students with logical-mathematical intelligence were software engineers $(66 \%)$ and most of students with interpersonal intelligence were informatics teacher $(63 \%)$.

On the basis of the revealed cognitive styles and abilities we can presume that the majority of our students enjoy learning independently within interactive multimedia educational environments.

The questionnaire was filled out by 124 students (I. $n=49$; II. $n=75$ ). The questionnaire included assessment of their e-learning product as well. Nearly $70 \%$ of the students thought that it is quite helpfully if the electronic curriculum takes into consideration student's preferences. Despite this fact $48 \%$ of the students confessed that their own product did not or hardly takes into consideration learners' differences, only $2 \%$ thought that their e-learning products fully takes into consideration students' preferences.

$9 \%$ of the students thought that their self-developed learning material fits the main aims. In total, students gave a mean as average to the quality of their own e-learning material products. In the feedback questionnaire we asked students' opinion about the role of learning style in e-learning. Nearly $50 \%$ of the students thought that it helps learning considerably, if the e-learner gets acquainted with the strengths and weaknesses of their own learning style.

According to the students' opinion in electronic learning environment, it is very important for the learner to be allowed to learn in their own style, this criterion may decide the success of the learning. More than half of the students think that the learning process is more efficient if a printed version of the course is available. This indicates the importance of precise transmission of information. 79\% of the students believe that the most effective learning method in higher education is through lectures with active student involvement (40\%), prefer materials to be also available through e-learning (39\%). The results of the questionnaire indicate that the respondent students consider that the blended learning method is the most efficient one, and there is also strong demand of tutorial support.

\subsubsection{Experiences of the Online Learning Model}

The experience of the semester was that we seemed to have integrated proper acivities into the course for the students with different learning styles. Their project works represented the highest quality until now, which presupposes that students understood the essence of the theory properly, extensively, and were able to apply it adequately with the help of the acquired tools and methods. We can observe improvement of students' critical thinking and assessment skills, shown by the fact that they were not entirely satisfied with their own performances.

The present study and analysis of the survey provided us three important conclusions:

- Students became much more confident learners by getting to know their own learning styles as well as its strengths and weaknesses in e-learning environments. 
- Students were not that much satisfied with their own products. This might also means that individual works of team members where not fine-tuned to fit coherently.

- The degree of collaboration between students remained an open question, as well as the ideal method for tracking and evaluation individual added value.

A further task is to assess the value added by individual students to the team work.

\subsection{Personalised Web-Based Collaborative Learning and Assessment Model}

As a third step in our research we have focused on the establishment of personalized team work and its suitable assessment. To achieve our goals we have to give attention to collaboration and to integrate the technological devices supporting efficient learning. For this purpose during the fourth semester of our research we concentrated on the conditions of feasibility and traceability of project based collaboration. We have introduced the use of OpenProject ${ }^{2}$ program and more conscious project planning, project follow up and multi-level evaluation of the results. In addition to the evaluation during the project we have established the fair distribution of the grades using self- and group-assessment.

The developed CECIP (Collaboration - Evaluation - Critical thinking - Individual assessment - learner Profile) model integrates the following features:

- Generating learner profile on the basis of learning styles, preferences, attitudes and expectations.

a. To identify learning styles students filled out an online MBTI and a FelderSilverman test. By the evaluation of these tests students got acquainted with the role of learning style in e-learning, and with the strengths and weaknesses of learning style dimensions. That makes them conscious about the complementary types that promote the efficiency of team work.

b. In order to inform students about the characteristics of their peers, they were asked to provide an introduction about themselves, their added value, skills and expectations toward the course.

This data was available for all students of the course during the whole semester. The learner profile does not modify the course but helps with organisation, facilitating the learning process and the composition of project teams.

- Learning methods applied in our model: project work, group and individual work. The groups prepared project plans in which a responsible person was dedicated to each task, the duration of each task was estimated and progression of tasks were build to achieve coherent results.

- The achievement of the learning goals were based on Bloom taxonomy (Krathwohl, 2002) relying on active student and teacher knowledge building and evaluation methods. We developed the online knowledge base on the portal of the course.

a. Knowledge: The course material necessary for the learning of theoretical and practical part of the knowledge was available on-line and each group received

\footnotetext{
${ }^{2}$ OpenProject: http://openproj .org/.
} 
one chapter to develop as e-learning material. The students created an online knowledge base by setting up the "golden rules". The application of golden rules was mandatory for the development of their own learning material.

b. Understanding: Students got acquainted with creating mindmaps, and using authoring tools through sequential e-learning materials and practical hands on lab activities.

c. Application: They identified and critically analysed the above listed principles in the works submitted by previous-year-students.

d. Analysis: They actively analysed and evaluated their own impressions on different presentations they were exploited to during an interactive lecture.

e. Synthesis: They had to apply all what they learned in theory and practice within their own tasks to make a coherent final group work in collaboration.

f. Evaluation: They evaluated their own and the others' works.

- One of the most important part of the model is the evaluational strategy. In a collaborative e-learning environment value added by individuals, the performance and the acquired knowledge in a project work is very important to be traced with proper evaluation strategy, because in this educational model teacher cannot monitor students' individual performances. In an electronic educational environment self-evaluation and peer-evaluation has more importance. The used evaluational strategy has an essential role in knowledge-building, thus the evaluation of the project and individual work emerged from the following elements:

a. Students evaluate the multimedia materials made in the previous semesters by other using pre-determined evaluation criteria.

b. The students and the teacher together assess all their own development of multimedia materials on the basis of predetermined evaluation criteria and students then improved their work according to the assessment.

c. Students also evaluated their team-members' attitudes, collaboration and work as part of the online evaluational strategy.

d. The teams receive collective grade points for their whole project work, so they need to divide it according to individual added value.

e. Individual grades are issued by the teacher in accordance with the previous agreement.

- The quality and effectiveness of the used methodology was ensured by the students' feedbacks. Students submitted an online questionnaire their opinion about their own learning style, they evaluate their own activities and product and how the aims of the course were fulfilled.

\section{Results}

In this semester we had only 32 students, since due to the switch to the Bologna twostaged qualification scheme we could offer the course only to left over students from the previous qualification system. We generated the learner's profile online. 


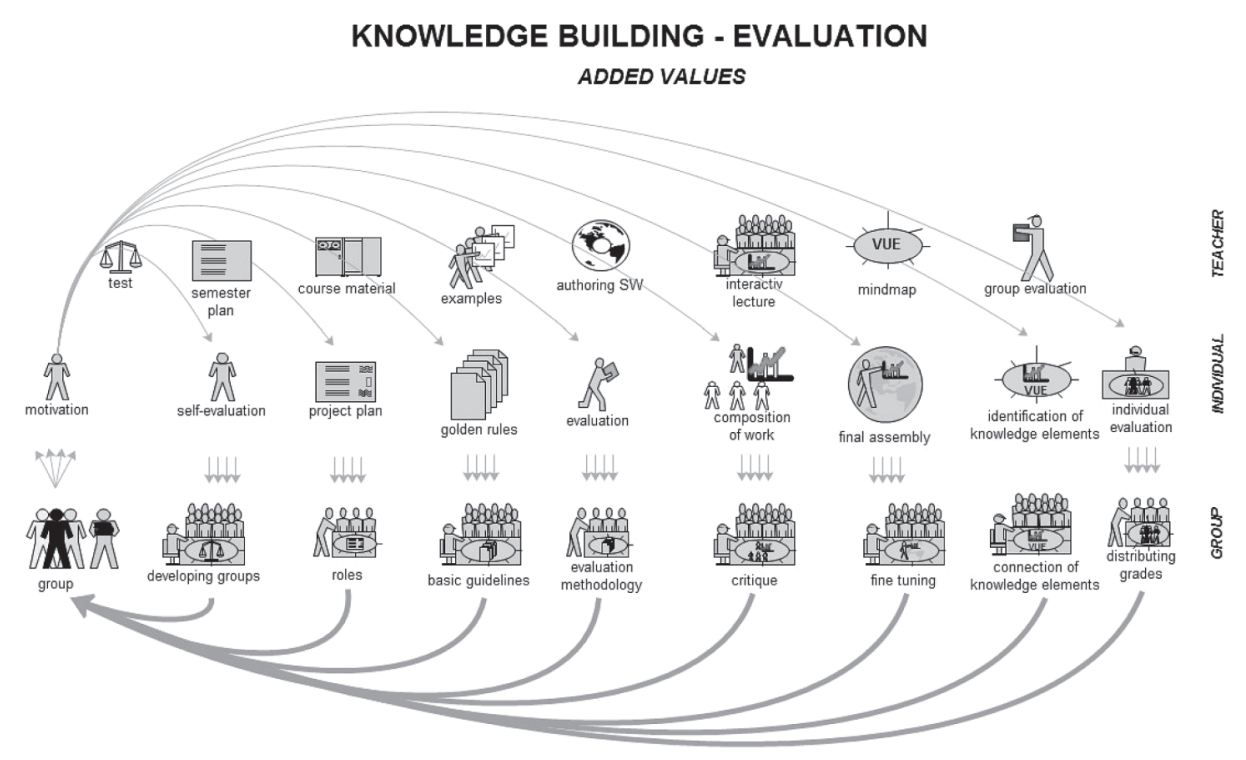

Fig. 5. Knowledge-building and evaluation model what we used.

From the MBTI test the most frequent styles are ISTJ (20\%), ESTJ (12\%) and ESTP $(20 \%)$. If we examine the effect of a single factor, then the sensing (68\%), thinking (72\%) factors dominate. These results are similar to that of the previous semesters and typical for students specialized as programmer and informatics teacher.

According to Felder-Silverman test, more than $80 \%$ of the students are active, sensing and visual, so these three types can't be evaluated in more details. The sequential/global types show bigger difference: $52 \%$ of the students were sequential and $48 \%$ of them global.

The introductory course pages were accessible by everyone, so project teams could develop at an early stage. According to the inputs given on self-introduction sequential students (75\%) thought that web-, sound- and video-development, while global students (72\%) thought that previous project-experience and good team-work are the important factors in the project. This result is in agreement with international literature in case of these two types. We also found that $44 \%$ of the students took the course only because they needed credits, the expectation of the others were to acquire practical knowledge (33\%) or to get acquainted with some special software (17\%).

\subsection{Activity and Efficiency}

We measured students' activity by their participation in knowledge-building, their activity in the forums, their tasks according to project-plans, online evaluations and the tests. Preparing project plans has a lot of advantages. Tasks became more transparent for the students when divided into parts, identifying sub-tasks. Communication between the students was crucial, too because the groups prepared project plans in which a re- 
sponsible person was dedicated to each task and the duration of each task was estimated. Project plans helped in tracing which activities were chosen by students with different preferences. The sequential students chose the task of project-planning and the interactive elements, and the global students chose the development of design-plan, integrating the parts of the tasks and the testing.

\subsection{Results of Evaluations}

Students evaluated the e-learning materials developed by the previous-semester-students. We had 51 evaluations, from what we can say: Students' opinion was very similar sometimes, and very different on the other hand. In general more students agreed on the good solutions than on bad practise. The efficient use of sound had the worst evaluation (1.7 five grade Likert scale), and the second worst one was the fine-tuning of the material as a whole (3.4). Navigation and visualisation got also medium score. The suitability of text integration got the biggest points (3.92). We didn't find significant difference between the global and the sequential students except for their judgement on presentation: While global students gave 4.0 points, sequential students gave 3.6 points for it.

Students made online pre-evaluation on project-member's attitude, individual performance, cooperation and responsibility. Students were very critical because a teammember's inadequate performance could jeopardise the other members' work and the whole project. Peer reviews showed great deviation on the effectiveness of team work. Their own responsibility and experience got 3.56 in average.

The evaluation questionnaire included assessment of their e-learning products as well. $19 \%$ of the students think that their e-learning product fully takes into consideration students' preferences. This means progress with respect to the previous $2 \% .52 \%$ of the students think that their own project product is good, but only $10 \%$ of them think that it fits to the aims dictated by the "golden" rules.

The questionnaire confirmed that the students' opinion is similar like in previous semesters: in electronic learning environments it is very important for the learner to be allowed to learn with own style (96\%), the learning process is more efficient if a printed version of course is available (71\%), and it helps learning considerably, if the e-learner gets acquainted with the strengths and weaknesses of their own learning style (81\%). The respondent students considered that the blended learning method is the most efficient one, and there is also strong demand of tutorial support (67\%). The same numbers of the students (67\%) think that preparing project-plans produced effectiveness and more transparency in the team-work. More students thought important the e-learning function of visual elements $(81 \%)$ than the function of auditive elements $(43 \%)$.

We can conclude that most students have been satisfied by their own grades compared to the result of their team even though some teams expected better total score. A single student was protesting against the grade given to him by his team. This team divided the points again with agreement of most of its members. Since the number of students in this semester was quite low we would like to broaden the application of this method in the future. 


\section{Discussions}

This study provides an empirical investigation based on case-studies on personalised and collaborative learning set-ups in a blended learning frame. The identified teaching approaches were developed and tested in a particular higher education context. This approach integrates strategies and methods which enhances the effectiveness and efficiency of our students learning experiences.

Being aware of the significance of learning styles may enhance students' selfawareness for their own and others learning strengths and weaknesses which is an important skill for future multimedia content developers.

Most of the students experienced online collaborative environment for the first time within our course. Their most important experiences in our blended learning context were team responsibility and peer dependency. Students felt that working in project teams, keeping deadlines; dividing grades need more attention and responsibility than traditional teaching methods. Collaborative knowledge building seems to be more effective in identifying critical rules within the overall theory to be implemented even if not followed in practice.

Generally, students liked and actively took part in interactive lectures; and in declaration of "golden rules". They assessed severely previous year's students' e-learning materials; they actively took part but found it difficult to apply these rules within their own developments.

\section{Conclusions and Future Work}

Electronic learning and learning environment do not guarantee efficient learning by themselves. The role of the teacher as a guide cannot be neglected. But, even the blended learning combination doesn't automatically provide success if the model is not based on sound methodological basis. The development of such methodology for our course "Designing multimedia materials" was what we have explained in our paper as an example, requiring efficiency and concentration on the target aims due to the complexity of its context.

In this paper we firstly presented our experimental course where we demonstrated the function of learning style in e-learning. Analyzing student's behaviour and attitude in an online learning environment we found that students with different learning style preferences have different attitudes within online courses. In our four semesters research period we used several instruments for identifying students learning style: MBTI test which is widely used in business, Gardner's Multiple Intelligences theory, Group Embedded Figures Test (GEFT), Felder-Silverman Index of Learning Style (ILS) questionnaire. Results of these were as follows:

- Results of the MBTI test proved to show a characteristic picture of students tested: them mostly being ISTJ and ESTJ as Sensing + Thinking + Judgeing, which are considered to be positive characteristics for program designers.

- Results of Gardner test showed that our students are mostly logical-mathematical and had interpersonal intelligences. 
- Results of GEFT test proved to show a characteristic picture of students tested as they were all program designers who by definition should be field-independent in order to perform well in this area.

- Using the Felder-Silverman ILS questionnaire we discovered important and relevant learning preferences for web-based educational systems. While the other tests identified characteristics within tested students, the Felder-Silverman test made distinction between students much more.

Secondly, we presented our collaborative learning model with respect to learning style. This model required active, collaborative learning, but collaboration was difficult to observe and interactions between the students were problematic to identify, while student's individual achievement needed identification also.

Thirdly, we presented our refined project based online collaborative student centred learning model (CECIP), with respect to learning style and learner preferences by generating learner profile, which required active individual and collaborative knowledge building and a refined evaluation strategy. Cooperation was more defined and planned, thus better to monitor, while evaluation was performed in several layers (using, evaluation of previous work, self-evaluation, peer evaluation and collective grading with agreed added value division.

Finally we summarize the list of used applications and web 2.0 technologies grouped according to the types of tasks within the learning process of the CECIP model, describing the different supported Learning Styles:

(1) Individual learning. This learning approach supports the learning process of reflective, introverted, intrapersonal students who prefer self supporting work. In the LMS learning material one can choose different representations: visual and auditive elements, practical examples. The mindmap navigation feature of the learning materials support sequential and global learning processes. The applied tools and technologies used:

FreeMind (http://freemind. sourceforge.net/wiki/index.php/ Main_Page), VUE (http://vue.tufts.edu/),

CamStudio (http: / / camstudio.org/),

GoogleDocs (https://docs.google.com), Prezi (http://prezi.com/), SlideShare (http: / / www. slideshare. net/), MS Office, Delicious (http: / /www.delicious.com/) and step-by-step learning materials.

(2) Collaborative knowledge building. In this part the whole group develops collaboratively the learning material. This learning method fits to active, interpersonal, extraverted, divergent, field dependent learners who understand the learning material much better when they learn and work actively in groups. The applied tools and technologies are the following: Wiki, forum and chat which tools were integrated into the learning environment.

(3) Interactive experiential seminars integrating practice monitoring, group discussion, collective analysis. After every task students give feedback on their experiences. This method helps the learning process of active, theoretical, accommodative, sensing, extraverted, linguistic, verbal, interpersonal learners. This 
method was realised with face to face seminars, with a forum integrated in LMS and with an online questionnaire. The applied tools and technologies are the following: MS PowerPoint, Prezi (http://prezi.com/), SlideShare (http: / /www.slideshare.net/), and Forum integrated in LMS.

(4) Analysis and evaluation of other projects developed by previous-year-students. This method helps visual, thinking, sensing, inductive learning. The applied tools and technologies are the following: web pages with different media elements integrated, GoogleDocs (https: / / docs .google.com).

(5) Project work, project plan. Students have to develop their tasks in project work. Students create project plans which integrate timetable and task list. This learning method helps learning process of judging, active, reflective, divergent learners. For the development and management of the project based team work we can use webbased Zoho project or OpenProject.

(6) Implementation of a specific task. In their project work students have to develop solutions to complex, real life problems. This approach helps accommodative and sensing students. The applied tools and technologies are the following: MS Office, GoogleDocs, YouToube, Picasa, Delicious, authoring software (HTML editor, Audacity (http://audacity.sourceforge.net/), Flash, Gimp (http://www.gimp.org) and Inkscape (http://inkscape.org/)), mindmapping tools, video production tools and all sorts of digital storytelling tools.

(7) Evaluation methods. Self- and peer evaluation is preferred by active, reflective and thinking learners. The key technology supporting evaluation is GoogleForm service.

We can summarize that our effective blended learning model CECIP, which is based on (C) collaborative construction of student's knowledge (E) developing evaluation and assessment skills (C) developing critical thinking skills, (I) integrating individual evaluation and $(\mathrm{P})$ generating learner profile, not only it is close to the theory of Vygotsky but also insists to take into consideration all of its elements.

The existing learning management systems do not support automatically possibilities for implementing our blended learning model. Our future work is to develop such extensions in order to be able to adapt the model within our own LMS.

Acknowledgements. The project is supported by the European Union and co-financed by the European Social Fund (grant agreement No. TAMOP 4.2.2./B-10/KMR-2010-0030).

\section{References}

Anderson, T. (2008). Theory and Practice of Online Learning. Athabasca, AU Press, 47-52.

Béres, I., Magyar, T., Turcsányi-Szabó, M. (2008a). E-tanulás hatékonyságának feltételei a felsőoktatásban (Criteria for efficiency of e-learning in higher education). Informatika a felsőoktatásban 2008 (Informatics in Higher Education Conference, Debrecen.

Béres, I., Magyar, T., Turcsányi-Szabó, M. (2008b). The function of cognitive styles in the development of effective electronic courseware for higher education. GAMF Reports, XXII, 91-98. 
Béres, I. (2009). Tanulási stílusok e-tanulási szerepe (Learning styles and the role of e-learning). I. OktatásInformatikai Tanulmánykötet (Journal of Educational Informatics, 1), ELTE Eötvös Publishing, Budapest, 71-78.

Bonk, C.J., Zhang, K. (2008). Empowering Online Learning: 100+ Activities for Reading, Reflecting, Displaying, and Doing. San Francisco, CA, Jossey-Bass.

Brogan P., (2008). E-Learning Standards, The E-Learning Handbook. Pfeiffer, San Francisco. A Framework for Enabling the Creation and Distribution of High-Quality, Cost-Effective Web-Delivered Instruction, by Pat Brogan.

Carliner, S., Shank, P. (2008). The E-Learning Handbook. Pfeiffer, San Francisco.

Clark, R.C., Lyons, C. (2004). Graphics for Learning. Pfeiffer.

Coffield, F., Moseley, D., Hall, E., Ecclestone, K. (2004). Learning Styles and Pedagogy in Post-16 Learning. Learning and Skills. R. C., London.

Cook, G. (NA). Research paper for Master of Information Technology. Learning Activity Styles for Online Learning.

Collis, B., Moonen, J. (2004). Flexible Learning in a Digital World, 2nd edn. London, Routledge and Falmer.

Felder, R., Silverman, L. (1988). Learning and teaching styles in engineering education. Engr. Education, 78(7), 674-681. http://www4.ncsu.edu/unity/lockers/users/f/felder/public/Papers/ LS-1988.pdf.

Felder, R. (1993). Reaching the second tier: learning and teaching styles in college science education. J. College Science Teaching, 23(5), 286-290.

http: / /www4 .ncsu.edu/unity/lockers/users/f/felder/public/Papers / Secondtier.html.

Henke, H. (2001). Learning Theory: Applying Kolb's Learning Style Inventory with Computer Based Training.

Holmes, B., Gardner, J. (2006). E-learning: Concepts and Practice. Sage, London.

Keirsey, D. (1998). Please Understand Me, II. Prometheus Nemesis Book Company. www. keirsey.com/.

Kolb, D.A. (1984). Experiential Learning: Experience as the Source of Learning and Development. PrenticeHall, Englewood Cliffs, New Jersey.

Krathwohl, D.R. (2002). A Revision of Bloom's Taxonomy: An Overview. EBSCO.

Life Long Learning Programme of the European Union in the EACEA Website. http://ec.europa.eu/dgs/education_culture/publ/pdf/ll-learning/ europe_en.pdf.

McLoughlin, C. (2007). Adapting e-learning across cultural boundaries: a framework for quality learning, pedagogy, and interaction. In: Edmundson, A. (Ed.), Globalized E-Learning Cultural Challenges, London, Information Science Publishing, 223-238.

Miyake, N. (2007). Computer Supported Collaborative Learning, The Sage Handbook of E-Learning Research, London, 248-265.

Pimentel, J.R. (1999). Design of Net-learning Systems Based on Experiential Learning. JALN, 32. http://www.aln.org/publications/jaln/v3n2/v3n2_pimentel.asp.

Rittschof, K. (2008). Field dependence-independence as visuospatial and executive functioning in working memory: implications for instructional systems design and research. Education Tech. Research Dev.

Salmon, G. (2002). E-tivities: the Key to Active Only Learning. Sterling, VA, Stylus Publishing Inc.

Siemens, G., Tittenberger, P. (2009). Handbook of Emerging Technologies for Learning. http://umanitoba.ca/learning_technologies/cetl/HETL.pdf.

Triantafillou, E., Demetriadis, S., Pombortsis, A., Georgiadou, E. (2004). The value of adaptivity based on cognitive style: an empirical study. British Journal of Educational Technology, 35(1), 95-106.

Vygotsky, L.S. (1978). Mind in Society: The Development of Higher Mental Processes. Cambridge, MA: Harvard University.

Vygotsky, L.S. (1986). Thought and Language. Cambridge, MA, MIT Press. 


\section{Appendix}

Questionnaire

Students' opinions of e-learning environments, and the role of learning styles in elearning.

* Obligatory

1. Student code: *

2. How important issue is the usability (speed, transparency, quality, user friendliness) within a digital learning environment? *

- O irrelevant

- little role

- 0 medium

- O important

- very important

3. In your opinion, how much help does the support services provide to the digital learning (user guide, help supply, forum)?*

- $\square$ not at all

- $\square$ hardly

- $\square$ medium

- $\square$ considerably

- $\square$ totally

4. In your opinion, does Learning Management Systems taking care of individual differences help acquiring the learning materials? *

- $\square$ not at all

- $\square$ hardly

- $\square$ medium

- $\square$ considerably

- $\square$ totally

5. In your opinion, does the existence of quality standards within a Learning Management System provide help in the learning process (and to what extent)? *

- $\square$ not at all

- $\square$ hardly

- $\square$ medium

- $\square$ considerably

- $\square$ totally

6. In your opinion, does the digital learning environment (interface, graphics quality, speed, functionality) effect the learning process (and to what extent)? *

- $\square$ not at all

- $\square$ hardly 
- $\square$ medium

- - considerably

- - totally

7. Do graphics, diagrams and visual elements, placed within an e-learning material support the learning process? *

- — not at all, disturbing

- - hardly

- $\square$ medium

- $\square$ considerably

- $\square$ totally

8. Do sound-elements in e-learning materials support better understanding of relationships and concepts? *

- — not at all, disturbing

- $\square$ hardly

- $\square$ medium

- $\square$ considerably

- $\square$ totally

9. In your opinion, what is the quality of the learning material prepared by yourself? $*$

- $\square$ quite bad, unusable

- $\square$ barely usable

- $\square$ usable

- $\square \operatorname{good}$

- - fully meets the targets

10. In your opinion, how do the diagrams in the learning material developed by yourself help understanding concepts and relationships? *

- $\square$ does not help at all

- $\quad 30 \%$ helpful

- — $50 \%$ helpful

- $\quad 70 \%$ helpful

- - $100 \%$ helpful

11. In your opinion, does considerations for individual differences within the learning material have effect (andto what extent) on the learning process? *

- $\square$ does not have any effect

- $\quad 30 \%$ helpful

- $50 \%$ helpful

- $70 \%$ helpful

- — $100 \%$ helpful 
12. Does the learning material developed by yourself takes into consideration learning differences? $*$

- - not at all

- ए hardly

- $\square$ in part

- - greatly

- ए totally

13. How well do you think a digital learning material can deepen knowledge? *

- not at all

- $\square$ hardly

- $\square$ in part

- $\square$ greatly

- $\square$ totally

14. How much better could the learning process be deepened if the digital learning material is accompanied by printed materials too? $*$

- - not at all

- - $30 \%$ more helpful

- $50 \%$ more helpful

- $\quad 70 \%$ more helpful

- — $100 \%$ more helpful

15. How important is it for a learner to learn at own pace? $*$

- $\square$ not at all

- — it has only a little role

- ए medium

- $\square$ it is important

- - very important, it could decide the success of the learning

16. While learning with digital learning materials, how important is communication with the instructor and with other students? *

- - not at all, I would receive all the information through the material itself

- I little role

- ए medium

- - important

- - very important, it could decide the success of the learning process

17. When starting as employee, does it give you any advantage if you have already gone through a digital learning process during your university studies, taking into consideration that workplaces also utilise digital learning materials for capacity building? *

- - not at all

- - hardly any

- $\square$ medium 
- - considerably

- $\square$ totally

18. Which teaching method do you this is "most effective" in higher education? *

- - the teacher gives lectures/presentations

- - the teacher gives lectures/presentations, in which students are actively involved

- - the teacher explains in form of lecture/pesentation the material wich is digitally accessible

- - the student processes a digital learning materialwhich is supported by the teacher/tutor

- - the student processes the digital learning material independently/alone

19. In your opinion, are the features identified within the MBTI test characterise you? *

- $\square$ not at all

- ए hardly

- $\square$ in part

- $\square$ considerably

- $\square$ totally

20. In your opinion, are the features identified within the GEFT test characterise you? *

- not at all

- $\square$ hardly

- in part

- $\square$ considerably

- $\square$ totally

21. In your opinion, are the features identified aithin the Learning Styles Test (teszt2.xls) characterise you? $*$

- — not at all

- - hardly

- — in part

- - considerably

- $\square$ totally

22. Do you think it is important for students to learn about their own learning styles and when studying in an e-learning environment? *

- ए no at all

- ए a little

- ए medium

- [ considerably

- $\square$ very important 
23. In your opinion, do you think it is important (and if so, to what extent) that students recognise their own learning strengths and weaknesses? *

- $\square$ not at all

- - 30\% helpful

- $50 \%$ helpful

- $70 \%$ helpful

- - $100 \%$ helpful

I. Béres is an assistant professor at Budapest College of Communication and Business, Department of Methodology. Her research area is information technology and technology supported innovative teaching and learning methods, environments in higher education.

T. Magyar is an assistant professor at Budapest College of Communication and Business, Department of Methodology. Her research area is dyscalculia. She designs tests for the evaluation of it and creates educational programs for the development of students with dyscalculia. She graduated as mathematics and informatics teacher and is working on her $\mathrm{PhD}$.

M. Turcsányi-Szabó is an associate professor at Eötvös Loránd University, Faculty of Informatics, Department of Media Informatics and Technology and is the head of Media Informatics and Technology Group, which continuously produces and researches complex environments for learning. She graduated as program designer mathematician and has a $\mathrm{PhD}$ in informatics with more than 25 years of experience within research on technology enhanced learning.

\title{
Mokymosi stiliumi grindžiamas mišraus bendradarbiavimo mokymosi modelis su individualiu vertinimu
}

\author{
Ilona BÉRES, Tímea MAGYAR, Márta TURCSÁNYI-SZABÓ
}

Straipsnio autoriai siekia apibūdinti procesą, kaip įasmenintu saitynu pagrịsta bendradarbiavimo mokymo (mokymosi) metodologija susiformavo iš Vygotsky teorijos. Ši metodologija remiasi bendradarbiavimu, vertinimo ir įvertinimo igūdžiu formavimu, kritišku mąstymu, individualaus vertinimo ir mokinio profilio integravimu. Apžvelgiami teoriniai mokymosi stilių pagrindai ir strategijos.

Elektroninis mokymasis ir mokymosi aplinkos negarantuoja efektyvaus mokymosi. Mokytojo, kaip vadovo, vaidmuo negali būti ignoruojamas. 